Review article

\title{
Are eHealth interventions for adults who are scheduled for or have undergone bariatric surgery as effective as usual care? A systematic review.
}

\author{
Charlene Wright, MNut\&DietPrac ${ }^{\mathrm{a}, *}$, Rumbidzai N. Mutsekwa, MDiet\&Nut ${ }^{\mathrm{a}, \mathrm{b}, \mathrm{c}}$, \\ Kyra Hamilton, Ph.D. ${ }^{d}$, Katrina L. Campbell, Ph.D. ${ }^{\mathrm{a}, \mathrm{e}}$, Jaimon Kelly, Ph.D. ${ }^{\mathrm{a}, \mathrm{f}}$ \\ ${ }^{a}$ School of Medicine and Dentistry, Centre of Applied Health Economics and Menzies Health Institute Queensland, Griffith University, Southport, \\ Australia \\ ${ }^{b}$ Gold Coast Hospital and Health Service, Nutrition and Food Service Department, Queensland, Australia \\ ${ }^{c}$ School of Allied Health Sciences, Griffith University, Queensland, Australia \\ ${ }^{d}$ School of Applied Psychology, Griffith University, Queensland, Australia \\ ${ }^{e}$ Healthcare Excellence and Innovation, Metro North Hospital and Health Service, Queensland, Australia \\ ${ }^{f}$ Centre for Online Health, Faculty of Medicine, University of Queensland, Queensland, Australia
}

Received 30 March 2021; accepted 26 July 2021

Abstract

\begin{abstract}
This systematic review aimed to evaluate the effect of eHealth-delivered interventions for adults who undergo bariatric surgery on postoperative weight loss, weight loss maintenance, eating psychopathology, quality of life, depression screening, and self-efficacy. Six electronic databases were searched, with 14 studies (across 17 reports) included, involving 1633 participants. With substantial heterogeneity, qualitative descriptions have been provided. Interventions were delivered via an online program or internet modules $(n=2)$, telephone $(n=2)$, text messages $(n=2)$, videoconferencing $(\mathrm{n}=3)$, mobile application $(\mathrm{n}=1)$, and audiovisual media $(\mathrm{n}=1)$. Three studies included a combination, including internet modules and telephone $(\mathrm{n}=1)$, wireless fidelity scales, emails, and telephone $(n=1)$, and a combination of online treatment, weekly emails, and access to a private Facebook group $(n=1)$. All the eHealth interventions, except for one, implemented behavior change techniques, including self-monitoring, problem solving, social support, goal setting, and shaping knowledge. Both eHealth intervention and control groups lost weight across the included studies, and eHealth was found to be as effective as or more effective than the control for weight loss. Two studies measured weight loss maintenance; both eHealth and control groups regained weight in the longer term. The interventions showed significant improvement on assessment measures for eating psychopathology. In conclusion, when bariatric surgery patients have limited or no access to healthcare teams or require additional support, eHealth may be a suitable option. Future studies implementing eHealth interventions would benefit from reporting intervention components as per the behavior change techniques taxonomy and further consideration of delivering eHealth in a stepped care approach would be beneficial. (Surg Obes Relat Dis 2021; $\mathbf{\square}: 1-16$.) (C) 2021 American Society for Bariatric Surgery. Published by Elsevier Inc. All rights reserved.
\end{abstract}

\footnotetext{
*Correspondence: Charlene Wright, 1 Parklands Dr, Southport QLD 4215 Australia.
} 
The effectiveness of bariatric surgery for achieving weight loss and improvements in comorbidities is well established [1,2]. It results in superior improvement in glycemic-control metrics compared with various medical and lifestyle interventions [3], and greater excess weight loss with a lower chance of weight regain compared with non-surgical procedures [4]. Nevertheless, a substantial proportion of patients fail to meet clinically significant weight loss targets or experience weight regain $[1,5]$. The underlying causes leading to weight regain are multifactorial and relate to procedure- and patient-specific factors [6], such as poor adherence to postoperative dietary advice and disordered eating behaviors [7]. Considering the prevalence of weight regain postoperatively, efforts have been placed on determining treatment options. A systematic review and meta-analysis of randomized controlled trials by Stewart et al. [8], evaluated the effectiveness of lifestyle interventions delivered in-person, preoperatively, and/or postoperatively. The authors found that delivering behavioral interventions in addition to bariatric surgery resulted in improved postoperative weight loss outcomes, with the strongest evidence for postoperative interventions compared with preoperative. Rudolph et al. [9], conducted a review to determine the effects of behavioral management (delivered in-person and postoperatively) on weight loss and likewise found a positive effect [9]. Generally treatment was provided by dietitians trained and experienced in bariatric surgery or psychologists [9].

Continued follow-up between patients and their healthcare providers improves weight loss, weight loss maintenance, and mental health following bariatric surgery [1013]. Bariatric practices are commonly based in large, urban centers, and access to routine follow-up is challenging for patients outside of the city [14]. Increased travel distance to bariatric surgery sites is associated with less follow-up and hence potentially poorer outcomes [15-17]. Behavioral and psychosocial interventions delivered by a bariatric surgery healthcare provider may contribute to successful weight maintenance postoperatively, yet, with fewer follow-up consultations, this also limits the ability of the bariatric surgery team to identify difficulties and intervene accordingly [18].

eHealth assists with the delivery of healthcare services to regional and remote patients [19,20]. The World Health Organization defines eHealth as "the cost-effective and secure use of information and communications technologies in support of health and health-related fields, including healthcare services, health surveillance, health literature, and health education, knowledge, and research"[21]. Information communication technoloy examples include smartphone applications, text messaging, wearable devices, health information technology, telehealth, and videoconferencing [22]. A recent study by Maurice et al. [23] found bariatric surgical telehealth appointments were preferred by most patients residing in rural and remote locations. Consultation avoided significant travel time and cost for both patients and the health service, and improved equity and access to specialist services for rural and remote patients [23]. In addition, patients who are scheduled for or have undergone bariatric surgery report willingness to use various technologies to enhance their care, including email, text messages, phone calls [24]. Furthermore, existing systematic reviews show that the delivery of obesity prevention and treatment via eHealth is cost-effective and scalable [25-27], which may also be the case in bariatric surgery healthcare. eHealth could be offered to bariatric surgery patients when they would normally have nothing, be it due to barriers such as distance and travel, or offered in addition to usual care. Health systems with adequate resources for all cannot be taken for granted, and as COVID-19 has shown, the uptake of eHealth is a rapid response.

COVID-19 is producing a "natural experiment" as eHealth has become a necessary alternative to traditional face-to-face consultation. In the wider context, it may enable widespread adoption as it has provoked rethinking traditional, face-to-face models and addressed new and old barriers to healthcare access including psychotherapy [28]. It is important that healthcare and organizations stay abreast of eHealth developments and understand how they can be used to support and improve practice. Furthermore, during the COVID-19 pandemic and associated isolation, adults who had undergone bariatric surgery experienced increased binge eating, depression, loneliness, loss of control when eating, nervousness, snacking [29], grazing behaviors, and negative urgency [30]. In addition, there were decreases in social support, eating healthy food, and physical activity [29], resulting in postoperative weight gain [29], less total weight loss, and larger weight regain [30]. More patients experienced excessive weight regain compared with patients before the pandemic (20\% versus $4.5 \%$ ) [30]. Given that a substantial proportion of patients fail to obtain clinically significant weight loss targets or experience weight regain postoperatively and are vulnerable in times of crises such as the COVID-19 pandemic, additional interventions to address behaviors that lead to weight regain are required; eHealth is possibly a viable option.

The literature regarding the delivery of services and support via eHealth in the bariatric surgery population is limited. Coldebella et al. assessed the evidence related to telemedicine finding interventions, and outcomes were not comparable owing to study design heterogeneity [31]. Similarly, Messiah et al. [32] examined eHealth intervention studies among bariatric surgery patients within the REAIM framework and likewise found study designs varied widely. Efficacy was rarely reported in studies, as the majority were not randomized controlled trials. Furthermore, the primary outcomes of the included studies were feasibility and acceptability.

The efficacy of eHealth remains unclear, and with the rapid adoption of eHealth during COVID-19, further 
evaluation is warranted. In addition, considering weight regain is multifactorial, it is important to consider the effect of eHealth on eating psychopathology, quality of life, depression screening, and self-efficacy. Therefore, the aim of this review is to evaluate the effect of eHealth-delivered health service or support for adults who undergo bariatric surgery on postoperative weight loss, weight loss maintenance, eating psychopathology, quality of life, depression screening, and self-efficacy.

\section{Methods}

This systematic literature review was reported corresponding to the Preferred Reporting Items for Systematic Reviews and Meta-analyses (PRISMA) statement [33,34] and followed a protocol registered prospectively with the International Prospective Register of Systematic Reviews (PROSPERO registration: CRD42020178489).

\section{Search strategy}

Six electronic databases were searched, including the Cochrane Central Register of Controlled Trials (CENTRAL), Cumulative Index to Nursing and Allied Health Literature (CINAHL via EBSCOhost), EMBASE, PubMed (includes citations for articles from MEDLINE), Scopus, and Web of Science (via Clarivate Analytics), from database inception up to April 30, 2021. A combination of keywords designed for PubMed was used and converted to the other databases using CREBP-SRA Polyglot Search Translator [35]. For each database, converted keywords were checked for accuracy and modified as required. An experienced systematic review search librarian was consulted throughout. There were no language restrictions applied. The entire search strategy can be seen in Table S1 and is dated April 30,2021 . To identify any additional articles, reference lists of all included articles and relevant systematic reviews were screened.

\section{Eligibility criteria}

To be eligible for inclusion, each study had to satisfy criteria including 1) randomized control trials (RCTs), Quasi-RCTs, or controlled before and after studies with a comparator group receiving usual care or any control group with no intervention; 2) adult participants ( $\geq 18 \mathrm{yr})$; and 3) conducted in a population that has undergone or has a confirmed, scheduled bariatric procedure (waitlisted). Any open, laparoscopic, or endoscopic bariatric surgery procedure for the management of obesity was considered. Excluded procedures were banded gastroplasty, biliopancreatic diversion without a duodenal switch, jejunoileal bypass, nonadjustable banded gastric bypass, vertical banded gastroplasty, and vertical gastroplasty (unbanded), owing to them no longer being in use [36]. The fourth and final criterion included the provision of an intervention that provided healthcare support or services using eHealth including telephone, videoconferencing, smartphones, mobile devices, smartphone applications, online learning platforms, internet applications, email, or web-based techniques. This healthcare support or service could include those provided by a bariatric surgery healthcare provider, including a clinical nurse, dietitian, endocrinologist, exercise specialist, medical doctor, psychologist, or surgeon. If not described, the study was still included. The intervention could be delivered before and/or after the surgery. Requirements of the intervention were, if it was delivered preoperatively, a minimum duration of 2 weeks, and if delivered postoperatively a duration of $\geq 1$ month, as guided by prior studies [37]. Singlesession interventions were excluded.

\section{Study screening}

Duplicate records were identified and removed using Endnote (version 9.3.3). Title and abstract screening was conducted by 2 independent investigators (C.W. and R.M.) to identify potentially eligible studies. The full texts of these papers were then reviewed to confirm inclusion by 2 independent investigators (C.W. and R.M.); disagreements were managed by consensus or a third reviewer when required (J.K.). One publication in a language other than English was transcribed using Google Translate before the fulltext screening [38].

\section{Outcomes and data extraction}

The primary outcomes of this review were weight loss and weight loss maintenance. Weight loss could be measured by the change in weight status, total weight loss in kilograms or percentages, body mass index (BMI), and Reinhold classification of excess weight loss. Weight loss maintenance was defined as weight loss at $\geq 6$ months after final intervention contact. Secondary outcomes of this review included alternative forms of body composition measurement (i.e., muscle mass), quality of life, anxiety and depression screening, the incidence of comorbidity diagnoses, gastrointestinal symptoms, adverse events (mild, moderate, severe; including death and reversion/conversion rates), satisfaction, self-efficacy, physical activity outcomes, diet-related outcomes, disordered eating, cost-effectiveness, and interventions planned according to or informed by behavior change theories or techniques.

Data from the included studies were extracted into an electronic spreadsheet by the lead author (C.W.) and checked for accuracy by R.M. Where discrepancies were found, they were corrected through discussion. Items extracted included study characteristics (year, design, registration, location, duration and intervention timing, setting, funding, conflicts of interest, sample size, attrition), participant characteristics (age, sex, baseline preoperative BMI, comorbidities, type of bariatric surgery), intervention characteristics (delivery method, content, delivery personnel, 
objective, tailoring, behavior change techniques), and control characteristics (delivery method, content, delivery personnel, objective). The study aim, primary outcome, and associated measures of effectiveness were extracted in addition to the outcomes mentioned previously. Missing data were requested from the study authors or sourced through additional articles of the same study. The interventions targeted bariatric surgery patients in general, and the outcomes in this review correspond to the results for the entire group. In addition, any specific subgroups (i.e., bariatric surgery patients experiencing a specific type of problem) have also been detailed.

\section{Behavior change techniques}

Behavior change techniques applied in the interventions were examined using the Behavior Change Technique Taxonomy (BCTT) [39]. The BCTT is considered the standard for reporting on techniques in health behavior change literature [40] and includes 93 hierarchical techniques clustered into 16 groups [39]. Behavior change techniques defined by the BCTT were coded by the lead author in NVivo and consistency checked by author K.H., a behavioral scientist. Any disagreements were resolved through discussion. Techniques were coded according to exact phrases and specific terminology included in the BCTT description table [39].

\section{Quality assessment and evidence certainty}

The Cochrane Risk of Bias tool [41] was used to assess for risk of bias. This tool evaluates 1) selection; 2) performance; 3) detection; 4) attrition; 5) reporting; and 6) overall bias. Two investigators independently completed the assessment of study quality (C.W. and R.M.). Disagreements were managed by consensus.

\section{Statistical analysis}

Mean differences and $P$ values for statistical significance were extracted and analyzed for the primary outcomes of the review and the primary outcomes indicated by the study. Where possible, study interventions were compared with controls of usual care, minimal care, or no intervention. Statistically significant between-group comparisons over time were used to indicate intervention effectiveness for the stated primary outcomes or the overall intervention aim in the case that there was no primary outcome stated.

\section{Results}

The PRISMA flowchart can be seen in Fig. 1 identifying 4299 publications. After duplicates $(\mathrm{n}=1747)$ and nonrelevant records $(n=2508)$ were excluded, 44 reports underwent full text review. After this, 27 reports were excluded, leaving 14 studies reported across 17 studies involving 1633 participants for inclusion.

\section{Participant characteristics}

Studies were conducted in Australia and New Zealand (n = 4) [42-45], Canada $(\mathrm{n}=4)$ [46-49], Europe $(\mathrm{n}=3$ studies, reported across 5 publications) [50-54], the United States ( $\mathrm{n}=2$ studies, reported across 3 publications) [55-57], and Korea $(n=1)$ [58]. Among the studies, 10 were conducted as RCTs (reported across 13 publications) [43-47,49,51-57], 3 were controlled before and after studies [42,48,50], and 1 was a quasi-experimental design [58]. The majority of the study settings were tertiary or public hospitals ( $\mathrm{n}=8$ studies, reported across 9 publications) [42-44,48-50,52,53,58]. Two were conducted in a medical or local center (reported across 4 publications) [51,54-56], 1 in a public health service [47], 1 study was not sitespecific and recruited via social media [45], and 2 studies did not report the setting [46,57]. In all but 2 studies (reported across 3 publications) $[51,54,58]$, the predominant patient sex was female. The mean age ranged from 40 to 53 years. BMI at baseline (preoperative) ranged from 42 to $53 \mathrm{~kg} / \mathrm{m}^{2}$ and was not detailed in 3 studies [45,49,57]. Samples contained mostly mixed bariatric surgeries $(\mathrm{n}=6$ studies, reported across 8 publications) [49-55,58], or laparoscopic sleeve gastrectomy $(\mathrm{n}=2)[44,57]$, along with waitlist samples in preoperative interventions $(n=5)[42,43,46,47,56]$, and 2 not reporting detail $[45,48]$.

\section{Intervention characteristics}

Intervention characteristics are tabulated in Table S2. Six interventions were delivered preoperatively [42,43,46,47,56,58], and Kalarchian et al. [55] also delivered a postoperative intervention to the same sample. Four studies delivered the postoperative intervention without usual care $[45,48,49,51,54]$, and 4 were in addition to usual care $[44,50,52,53,57]$. Across the interventions, modalities varied and included an online program or internet modules [42,47], telephone $[46,49,55,56]$, text messages [43,44], videoconferencing [48,52,53], mobile application [57], and audiovisual media [58]. Three studies included a combination of modalities, with internet modules and telephone [51,54], wireless fidelity scales, emails, and telephone [50], and a combination of online treatment, weekly emails, and access to a private Facebook group [45]. Durations ranged from the minimum preoperative intervention of 2 weeks [58] to a maximum of 24 weeks [47]. Postoperatively, the minimum intervention was 8 weeks [45], and the maximum was 2 years [57].

The majority of interventions were delivered individually; only 1 study (reported across 2 publications) was carried out in a group setting [52,53], and another provided access to a private Facebook group [45]. Delivery personnel included a nurse manager [42], psychometrist [46], clinical and health psychologist [45], psychology graduate students [49], research coordinators [57], and the surgical team [50]. Six studies did not detail the delivery personnel involved [48,51,52,54-56,58]. For 3 studies delivery personnel 


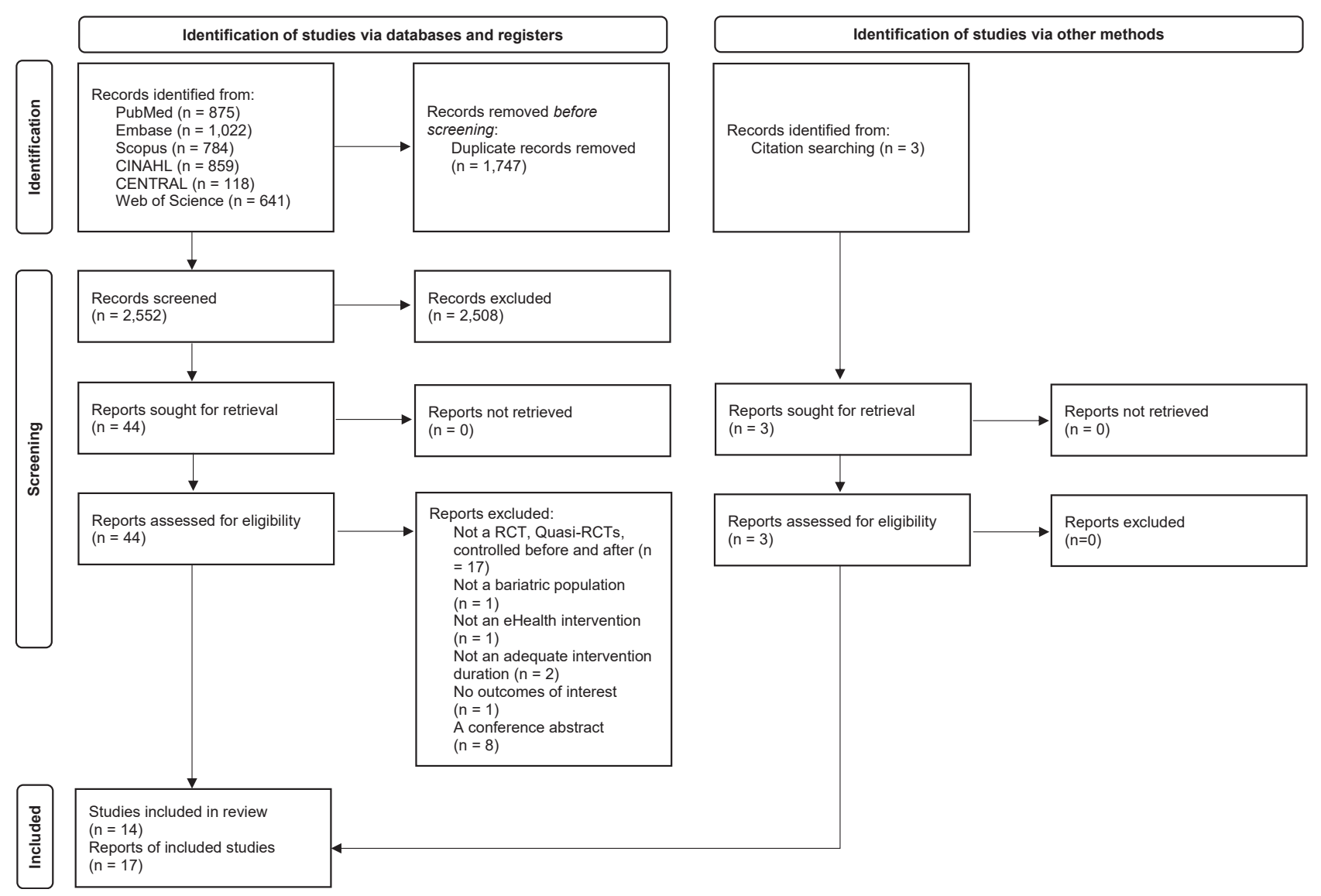

Fig. 1. Preferred Reporting Items for Systematic Reviews and Meta-Analysis flowchart of the search results and the included studies.

were not applicable owing to the nature of the intervention (i.e., text messages $[43,44]$ or an online program [47]).

Overall, timeframes of intervention commencement were described poorly, if at all. Studies implementing the intervention preoperatively were more likely to provide this detail, reporting commencement at 2 weeks [58], 4 weeks [43], and 4.7 months preoperatively [46]. With regard to postoperative interventions, only 2 provided this detail, with 1 commencing immediately after surgery [50] and another 18 months after surgery [44]. Two studies had inclusion criteria stating participants had to be $\geq 12$ months postoperative [45,49], yet did not detail intervention commencement timeframes. For all other studies, the intervention commencement was not detailed [42,47-49,51-57].

\section{Behavior change techniques}

The content included in the intervention was generally well described and can be seen in Table S3. All studies except for 1 [48] used behavior change techniques in the eHealth interventions as seen in Table 1. Of the 93 techniques listed in the taxonomy [39], 39\% were mentioned in the included studies ( $\mathrm{n}=$ 36). The mean number of techniques per intervention was 6 . The highest number used was 16 by Kalarchian et al. $[55,56]$, and the intervention was described in great detail within a book chapter [59]. The most commonly reported techniques, across the 13 interventions, were self-monitoring of behavior ( $\mathrm{n}=6$ interventions, reported across 9 publications) [42,46,47,49,52,53,55-57], shaping knowledge $(\mathrm{n}=6$ interventions, reported across 9 publications) [42,44,46,47,49,51-54], problem solving $(\mathrm{n}=5$ interventions, reported across 8 publications) $[43,46,47,49,52,53,55,56]$, social support (unspecified) $(n=$ 5 interventions, reported across 11 publications) [42,45,46,49,51,54-56], goal setting (outcome) $(\mathrm{n}=5$ interventions, reported across 11 publications) $[42,43,46,47,49,55,56]$, and self-monitoring of outcomes of behavior ( $\mathrm{n}=5$ interventions, reported across 8 publications) $[42,46,49,50,52,53,55,56]$. Of the 36 techniques identified 22 (61\%) were reported only once, with 12 originating from 1 study [44]. Lauti et al.'s [44] intervention design was guided by the behavior change wheel framework [60] and coded according to the taxonomy clusters rather than the individual techniques.

\section{Control characteristics}

Control characteristics are tabulated in Table S2. Control groups included routine clinic visits and assessments [46], supervised diet and activity programs [55,56], very-low- 
Table 1

Reported behavior change techniques according to the Behavior Change Technique Taxonomy (v1) [39], in intervention arms of the included studies with eHealth interventions delivered to adults who are scheduled for or have undergone bariatric surgery

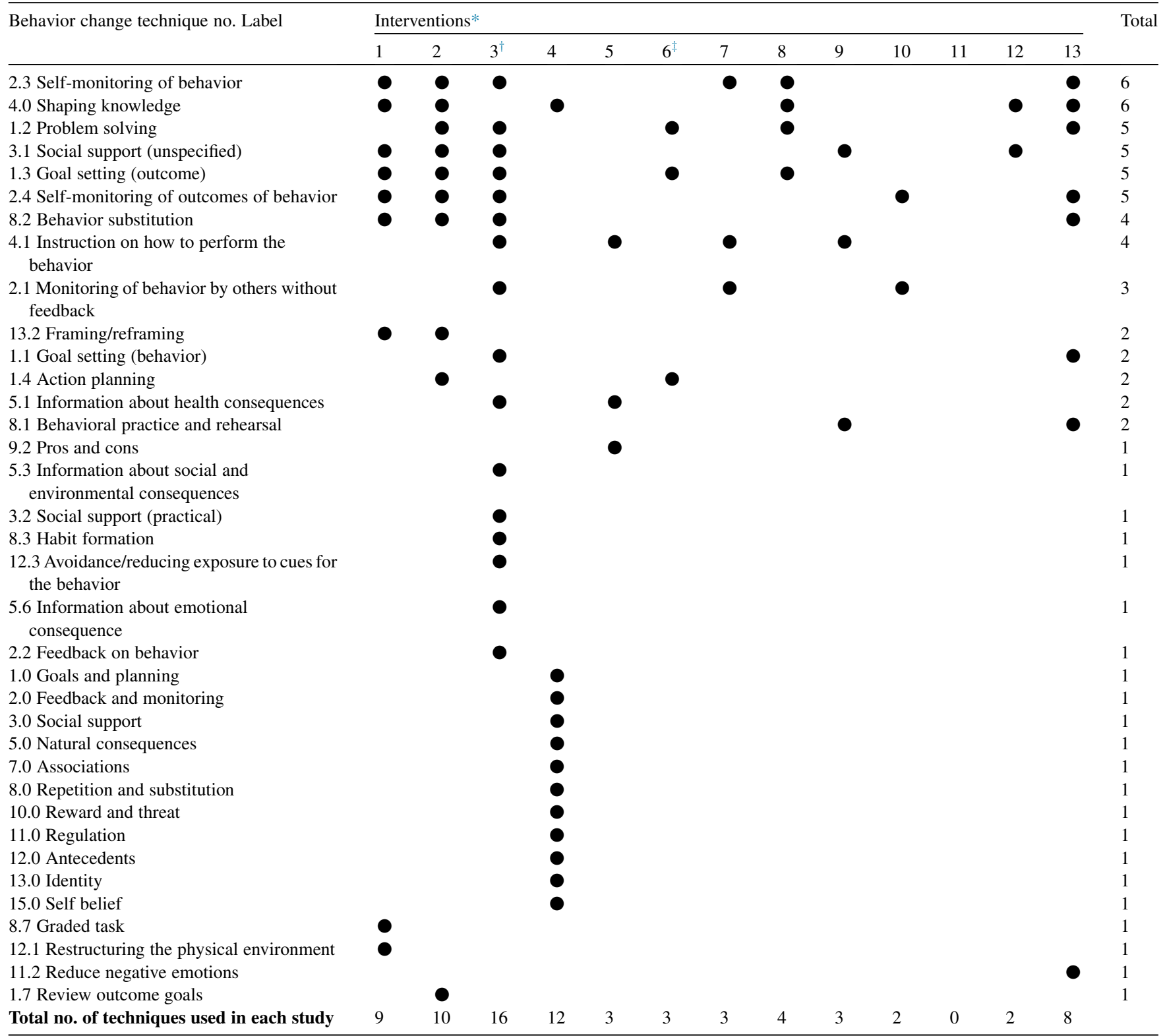

* Interventions are numbered in alphabetical order of author: $1=$ Brown et al. [42]; $2=$ Cassin et al. [46,49]; $3=$ Kalarchian et al. [55,56]; 4=Lauti et al. [44]; 5=Lee et al. [58]; $6=$ Lemanu et al. [43]; $7=$ Mangieri et al. [57]; $8=$ Padwal et al. [47]; $9=$ Stapleton et al. [45]; 10=Vilallonga et al. [50]; 11=Wang et al. [48]; $12=$ Weineland et al. [51,54]; 13 = Wild et al. [52,53] (Note: While the Cassin et al. references are different in that one was delivered preoperatively [46] and the other postoperatively [49], they both used the same intervention and hence have been combined in this table).

${ }^{\dagger}$ Obtained from published book chapter [59] as the intervention was only briefly described within the manuscript.

${ }^{\ddagger}$ Obtained from a prior publication [82], as the intervention was modeled from this study.

calorie-diet [43], and printed education material [47] preoperatively. Postoperative control groups included routine clinic visits including psychosocial follow-up and a monthly support group option [49], discharge or followup as required [44], and structured follow-up $[50,52,53,57]$. Several studies did not describe what the control group was exposed to or what usual care entailed $[42,45,48,51,58]$.

\section{Study aims and primary outcomes}

The study aim, primary outcome, and associated measures of effectiveness can be seen in Table 2. Primary outcomes of the studies included weight loss [42,44,45,49,50,52,53,55-57], eating psychopathology $[46,49,51,54]$, quality of life [51-54], self-efficacy $[52,53,58]$, preoccupation with body shape [51,54], 
Table 2

The study aim, primary outcome, measures, and intervention effect compared with control of included studies with eHealth interventions delivered to adults who are scheduled for or have undergone bariatric surgery

\begin{tabular}{|c|c|c|c|c|}
\hline \multirow[t]{2}{*}{ Author, year } & \multirow[t]{2}{*}{ Study aim } & \multirow[t]{2}{*}{ Primary outcome(s)* and measure(s) } & \multicolumn{2}{|c|}{$\underline{\text { Intervention effect compared to control }}^{\dagger}$} \\
\hline & & & Primary outcome(s) & Additional measure(s) \\
\hline \multicolumn{5}{|c|}{ Preoperative (intervention only) } \\
\hline Brown et al., 2016 [42] & $\begin{array}{l}\text { "To report on a prospective study of this pre- } \\
\text { hospital program as well as the 12-month } \\
\text { weight outcomes for the first cohort of patients } \\
\text { treated though this new pathway comparing } \\
\text { them to a control group of contemporaneous } \\
\text { patients treated through the standard } \\
\text { pathway." }\end{array}$ & $\begin{array}{l}\text { Weight loss via excess weight loss (\% } \\
\text { EWL) at } 12 \text { mo from the date of } \\
\text { surgery. }\end{array}$ & $\uparrow \operatorname{EWL} \%(P=.012)$ & $\begin{array}{l}\text { Satisfaction; eHealth intervention } \\
\quad \text { rated } 3.78 \text { out of } 4\end{array}$ \\
\hline Cassin et al., 2016 [46] & $\begin{array}{l}\text { "To examine the efficacy of a pre-operative } \\
\text { telephone-based cognitive behavioral therapy } \\
\text { (Tele-CBT) intervention versus standard pre- } \\
\text { operative care for improving eating } \\
\text { psychopathology and psychosocial } \\
\text { functioning." }\end{array}$ & $\begin{array}{l}\text { Eating psychopathology via Binge Eating } \\
\text { Scale (BES) and Emotional Eating } \\
\text { Scale (EES) at the end of the } \\
\text { intervention which was } 7 \mathrm{wk} .\end{array}$ & $\begin{array}{l}\downarrow \operatorname{BES}(P=.01) \\
\downarrow \operatorname{EES}(P=.002)\end{array}$ & $\begin{array}{l}\neq \text { SF-36 }(P>.05) \\
\downarrow \text { PHQ-9 }(\mathrm{p} P<.001)\end{array}$ \\
\hline Lee et al., 2020 [58] & $\begin{array}{l}\text { "Examine the effect of pre-operative information } \\
\text { by audio-visual media on patients before } \\
\text { bariatric surgery." }\end{array}$ & $\begin{array}{l}\text { NR; self-care knowledge via self-nursing } \\
\text { knowledge measurement tool for } \\
\text { presurgical education chairs for } \\
\text { gastrectomy patients, self-efficacy via } \\
\text { New General Self-Efficacy (NGSE), } \\
\text { and anxiety via State Trait Anxiety } \\
\text { Inventory (STAI) and the temperament } \\
\text { standardized for Koreans-state anxiety } \\
\text { at the end of the intervention which } \\
\text { was } 2 \text { wk. }\end{array}$ & $\begin{array}{l}\uparrow \text { Preoperative self-care } \\
\text { knowledge }(P<.001) \\
\uparrow \text { NGSE }(P=.001) \\
\downarrow \text { STAI }(P=.036)\end{array}$ & Nil \\
\hline Lemanu et al., 2018 [43] & $\begin{array}{l}\text { "To investigate whether a text message } \\
\text { intervention improves adherence to } \\
\text { preoperative exercise advice prior to } \\
\text { laparoscopic sleeve gastrectomy." }\end{array}$ & $\begin{array}{l}\text { Adherence to preoperative exercise } \\
\text { advice via the number of participants } \\
\text { partaking in } \geq 450 \text { metabolic } \\
\text { equivalent minutes (METmin-1) } \\
\text { exercise activity per week } \\
\text { preoperatively at the end of } \\
\text { intervention period, which was } 4-6 \mathrm{wk} \\
\text { in duration. }\end{array}$ & $\begin{array}{l}\uparrow \text { adherence to exercise ( } P \leq \\
.05 \text { ) }\end{array}$ & Nil \\
\hline Padwal et al., 2017 [47] ${ }^{\S}$ & $\begin{array}{l}\text { "Evaluate the clinical and economic outcomes of } \\
\text { two self-management programs of varying } \\
\text { intensity that are currently in use." }\end{array}$ & $\begin{array}{l}\text { Proportion of patients achieving 5\% } \\
\text { weight loss; weight loss (kg) and (\%); } \\
\text { and BMI change at } 6 \text { mo } \\
\text { postintervention, which was } 3 \mathrm{mo} \text { in } \\
\text { duration (full study duration of } 9 \mathrm{mo} \text { ). }\end{array}$ & $\begin{aligned} \neq & 5 \% \text { weight loss responders } \\
& (P=.28) \\
\neq & \text { weight loss }(\mathrm{kg})(P=.96) \\
\neq & \text { weight loss }(\%)(P=.79) \\
\neq & \text { BMI }(P=.88)\end{aligned}$ & $\begin{array}{l}\neq \text { SF-12 for the mental } \\
\text { component }(P=.24) \text { and the } \\
\text { physical component }(P=.58) \\
\downarrow \text { EQ-5D VAS score }(P=.03) \\
\neq \text { EQ-5D index score }(P=.33) \\
\neq \text { PHQ- } 8=.58) \\
\neq \text { Readiness to change }(P=.58) \\
\uparrow \text { WEL }(P=.01)\end{array}$ \\
\hline
\end{tabular}




\begin{tabular}{|c|c|c|c|c|}
\hline \multirow[t]{2}{*}{ Author, year } & \multirow[t]{2}{*}{ Study aim } & \multirow[t]{2}{*}{ Primary outcome(s)* and measure(s) } & \multicolumn{2}{|c|}{ Intervention effect compared to control ${ }^{\dagger}$} \\
\hline & & & Primary outcome(s) & Additional measure(s) \\
\hline \multicolumn{5}{|c|}{ Pre- and postoperative (intervention only) } \\
\hline $\begin{array}{l}\text { Kalarchian et al., } 2013 \\
\text { [56] (initial study } \\
\text { preoperative } \\
\text { intervention) }\end{array}$ & $\begin{array}{l}\text { "Document preoperative outcomes of a } \\
\text { behavioral lifestyle intervention delivered to } \\
\text { patients prior to bariatric surgery in } \\
\text { comparison to treatment as usual." }\end{array}$ & $\begin{array}{l}\mathrm{NR} \text {; weight loss }(\mathrm{kg}) \text { at the end of the } \\
\text { intervention, which was } 6 \text { mo in } \\
\text { duration. }\end{array}$ & $\uparrow$ weight loss $(P<.0001)$ & $\begin{aligned} \text { \# } & \text { EDE-Q for subjective } \\
& (P=.47) \text { and objective } \\
& (P=.72) \text { bulimic episodes } \\
\uparrow & \text { EBI }(P=.0004) \\
\neq & \text { BDI }(P=.54)\end{aligned}$ \\
\hline $\begin{array}{l}\text { Kalarchian et al., } 2016 \\
\text { [55] (follow-up with a } \\
\text { postoperative } \\
\text { intervention) }\end{array}$ & $\begin{array}{l}\text { "Evaluate whether a pre-surgery behavioral } \\
\text { lifestyle intervention improves weight loss } \\
\text { through 24-months post-surgery." }\end{array}$ & $\begin{array}{l}\text { NR; weight loss (\%) at follow up of } 6,12 \text {, } \\
\text { and } 24 \text { mo postoperatively. }\end{array}$ & $\begin{aligned} \neq & \text { weight loss at } 6 \mathrm{mo} \\
& (P=.12), 12 \mathrm{mo}(P=.12) \\
\neq & \text { weight loss at } 24 \mathrm{mo} \\
& (P=.02)^{\ddagger}\end{aligned}$ & Nil \\
\hline \multicolumn{5}{|c|}{ Postoperative (intervention only) } \\
\hline Wang et al., 2019 [48] & $\begin{array}{l}\text { "Compare post bariatric surgery appointment } \\
\text { adherence, psychosocial, and body mass index } \\
\text { (BMI) outcomes in patients that did or did not } \\
\text { use telemedicine." }\end{array}$ & $\begin{array}{l}\text { NR; appointment adherence via } \\
\text { percentage of appointment attended } \\
\text { and rate of dropout at } 2 \mathrm{yr} \text { postsurgery }\end{array}$ & $\begin{array}{l}\neq \text { appointment attendance } \\
\neq \text { rates of patients being lost } \\
\text { to follow-up }\end{array}$ & Nil \\
\hline $\begin{array}{l}\text { Weineland et al ., 2012a } \\
\text { [51] (initial study) }\end{array}$ & $\begin{array}{l}\text { "Evaluate the effects of acceptance and } \\
\text { commitment therapy for patients who } \\
\text { underwent bariatric surgery, with regard to } \\
\text { emotional eating, body dissatisfaction and } \\
\text { quality of life." }\end{array}$ & $\begin{array}{l}\text { NR; eating disorder behavior via eating } \\
\text { disorders examination questionnaire } \\
\text { (EDEQ), subjective binge eating via } \\
\text { subjective binge eating questionnaire } \\
\text { for bariatric surgery patients (SBEQ), } \\
\text { preoccupation with body shape via } \\
\text { body shape questionnaire short version } \\
\text { (BSQ), quality of life (QOL) via World } \\
\text { Health Organization Quality of Life } \\
\text { (WHOQOL-BREF), acceptance of } \\
\text { weight related thoughts and feelings } \\
\text { via acceptance and action } \\
\text { questionnaire for weight (AAQ-W) } \\
\text { measured at the end of the } \\
\text { intervention, which was 6-8 wk. }\end{array}$ & $\begin{aligned} & \downarrow \text { EDE-Q }(P=.047) \\
\downarrow & \text { SBEQ }(P=.006) \\
& \downarrow \text { BSQ }(P=.023) \\
\uparrow & \text { WHOQOL-BREF } \\
& (P=.022) \\
& \downarrow \text { AAQ-W }(P=.006)\end{aligned}$ & Nil \\
\hline $\begin{array}{l}\text { Weineland et al., 2012b } \\
\text { [54] (6-mo follow-up } \\
\text { study) }\end{array}$ & $\begin{array}{l}\text { "Examine both the maintenance of behavioral } \\
\text { change at a 6-month follow-up for the original } \\
\text { study and the processes that may be involved } \\
\text { in the outcomes." }\end{array}$ & $\begin{array}{l}\text { NR; Eating disordered behavior via EDE- } \\
\text { Q, binge eating via SBEQ, } \\
\text { preoccupation with body shape via } \\
\text { BSQ, QOL via WHOQOL-BREF, } \\
\text { acceptance of weight related thoughts } \\
\text { and feelings via AAQ-W, at } 6 \text { mo. }\end{array}$ & $\begin{array}{l}\downarrow \text { EDE-Q }(P=.067) . \\
\neq \text { SBEQ }(P=.29) \\
\downarrow \text { BSQ }(P=.024) \\
\uparrow \text { WHOQOL-BREF } \\
\quad(P=.007) \\
\downarrow \text { AAQ-W }(P=.013)\end{array}$ & Nil \\
\hline $\begin{array}{l}\text { Stapleton et al., } 2020 \\
\text { [45] }\end{array}$ & $\begin{array}{l}\text { "Assess whether post-surgery care comprising } \\
\text { Emotional Freedom Techniques, an emerging } \\
\text { energy psychology intervention, combined }\end{array}$ & $\begin{array}{l}\text { NR; weight loss via BMI at the end of the } \\
\text { intervention which was } 8 \mathrm{wk} \text { and at } 6 \\
\text { mo postintervention. }\end{array}$ & $\begin{array}{l}\neq \mathrm{BMI} \text { at the end of the } \\
\text { intervention and } 6 \text { mo } \\
\text { postintervention }(P=.917)\end{array}$ & $\begin{array}{l}\downarrow \text { TFEQ-18 }(P=.001) \\
\neq \text { FCI }(P=.328) \\
\neq \text { RSE }(P=.072)\end{array}$ \\
\hline
\end{tabular}




\begin{tabular}{|c|c|c|c|c|}
\hline \multirow[t]{2}{*}{ Author, year } & \multirow[t]{2}{*}{ Study aim } & \multirow[t]{2}{*}{ Primary outcome(s)* and measure(s) } & \multicolumn{2}{|c|}{ Intervention effect compared to control $^{\dagger}$} \\
\hline & & & Primary outcome(s) & Additional measure(s) \\
\hline Cassin et al., 2020 [49] & $\begin{array}{l}\text { "Examine correlates of food addiction among } \\
\text { postoperative bariatric surgery patients; } \\
\text { compare the clinical characteristics of patients } \\
\text { who meet "diagnosis" for food addiction at 1- } \\
\text { year post-surgery to those who do not; and } \\
\text { examine whether Tele-CBT improves food } \\
\text { addiction symptomatology among the subset } \\
\text { of individuals who meet "diagnosis" for food } \\
\text { addiction at 1-year post-surgery." }\end{array}$ & $\begin{array}{l}\text { NR; food addiction symptomatology via } \\
\text { modified Yale Food Addiction Scale } \\
2.0 \text { (mYFAS } 2.0 \text { ) at postintervention } \\
\text { (3-mo duration, which equated to } 15 \\
\text { mo postoperative) and } 18 \text { mo } \\
\text { postoperatively ( } 3 \text { mo } \\
\text { postintervention). }\end{array}$ & $\begin{array}{l}\downarrow \text { mYFAS } 2.0 \text { symptom } \\
\quad \text { scores }(P=.027) \\
\text { postintervention } \\
\neq \text { mYFAS } 2.0 \text { symptom } \\
\text { scores at follow-up } \\
(P=.772) .\end{array}$ & Nil \\
\hline \multicolumn{5}{|c|}{ Postoperative (intervention plus usual care) } \\
\hline Lauti et al., 2018 [44] & $\begin{array}{l}\text { "Determine the effectiveness of text message } \\
\text { support in reducing weight regain following } \\
\text { sleeve gastrectomy." }\end{array}$ & $\begin{array}{l}\text { Weight loss via EWL\% at mid } \\
\text { intervention ( } 6 \text { mon) and at the end of } \\
\text { the intervention period ( } 12 \mathrm{mo}) \text {. }\end{array}$ & $\begin{array}{l}\neq \mathrm{EWL} \% \text { at } 6 \mathrm{mo}(P=.273) \\
\text { and } 12 \mathrm{mo}(P=.456)\end{array}$ & $\begin{array}{l}\neq \mathrm{BMI} \text { at } 6 \mathrm{mo}(P=.106) \text { and } 12 \\
\mathrm{mo}(P=.452) \\
\neq \mathrm{TBW} \% \text { at } 6 \mathrm{mo}(P=.148) \text { and } \\
12 \mathrm{mo}(P=.339) \\
\neq \text { BAROS at } 6 \mathrm{mo}(P=.650) \text { and } \\
12 \mathrm{mo}(P=.092)\end{array}$ \\
\hline Mangieri et al., 2019 [57] & $\begin{array}{l}\text { "Examine the use of mHealth technology in a } \\
\text { bariatric surgery population to evaluate effects } \\
\text { on weight loss following surgery." }\end{array}$ & $\begin{array}{l}\text { Weight loss via EWL\% and excess BMI } \\
\text { loss (EBL\%) at mid intervention ( } 12 \\
\text { mo) and the end of the intervention ( } 24 \\
\text { mo). }\end{array}$ & $\begin{array}{l}\uparrow \mathrm{EWL} \% \text { at } 12 \mathrm{mo}(P=.047) \\
\text { and at } 24 \mathrm{mo}(P=.0078) \\
\uparrow \mathrm{EBL} \% \text { at } 12 \mathrm{mo}(P=.0007) \\
\text { and at } 24 \mathrm{mo}(P=.048)\end{array}$ & Nil \\
\hline $\begin{array}{l}\text { Vilallonga et al., } 2013 \\
\text { [50] }\end{array}$ & $\begin{array}{l}\text { "Evaluate the possibility of using Internet of } \\
\text { Things technology in morbidly obese } \\
\text { patients." }\end{array}$ & $\begin{array}{l}\text { NR; weight loss via EWL\% at } 9 \text { mo } \\
\text { postoperatively/end of study. }\end{array}$ & $\begin{array}{l}\text { Between group analysis not } \\
\text { performed }\end{array}$ & $\begin{array}{l}\text { BMI; between group analysis not } \\
\text { performed }\end{array}$ \\
\hline $\begin{array}{l}\text { Wild et al., } 2015 \text { [52] } \\
\quad \text { (initial study) }\end{array}$ & $\begin{array}{l}\text { "The Bariataric Surgery and Education (BaSE) } \\
\text { study aimed to assess the efficacy of a } \\
\text { videoconferencing-based psychoeducational } \\
\text { group intervention in patients after bariatric } \\
\text { surgery." }\end{array}$ & $\begin{array}{l}\text { Weight loss in kg, health-related QOL via } \\
\text { 36-Item Short Form Health Survey } \\
\text { (SF-36) and self-efficacy via General } \\
\text { Self-Efficacy (GSE) at } 6 \text { mo and } 12 \text { mo } \\
\text { postoperatively. }\end{array}$ & $\begin{aligned} & \neq \text { weight loss at } 6 \mathrm{mo} \\
&(P=.92) \text { and } 12 \mathrm{mo} \\
&(P=.78) \\
& \neq \text { SF-36 at } 6 \mathrm{mo}(P=.84) \\
& \text { and } 12 \mathrm{mo}(P=.39) \\
& \neq \text { GSE at } 6 \mathrm{mo}(P=.66) \text { and } \\
& 12 \mathrm{mo}(P=.19)\end{aligned}$ & $\begin{array}{l}\neq \mathrm{EWL} \% \text { at } 6 \mathrm{mo}(P=.65) \text { and } \\
\text { at } 12 \mathrm{mo}(P=.73) \\
\neq \mathrm{TBW} \% \text { at } 6 \mathrm{mo}(P=.78) \text { and } \\
12 \mathrm{mo}(P=.81) \\
\neq \mathrm{BMI} \text { at } 6 \mathrm{mo}(P=.86) \text { and at } \\
12 \mathrm{mo}(P=.82) \\
\neq \mathrm{PHQ}-9 \text { at } 6 \mathrm{mo}(P=.32) \text { and } \\
12 \mathrm{mo}(P=.18) \\
\neq \mathrm{EDE}-\mathrm{Q} \text { at } 12 \mathrm{mo}(P=.59) \\
\neq \mathrm{GSE} \text { at } 6 \mathrm{mo}(P=.66) \text { and } 12 \\
\text { mo }(P=.19)\end{array}$ \\
\hline
\end{tabular}

(continued on next page) 


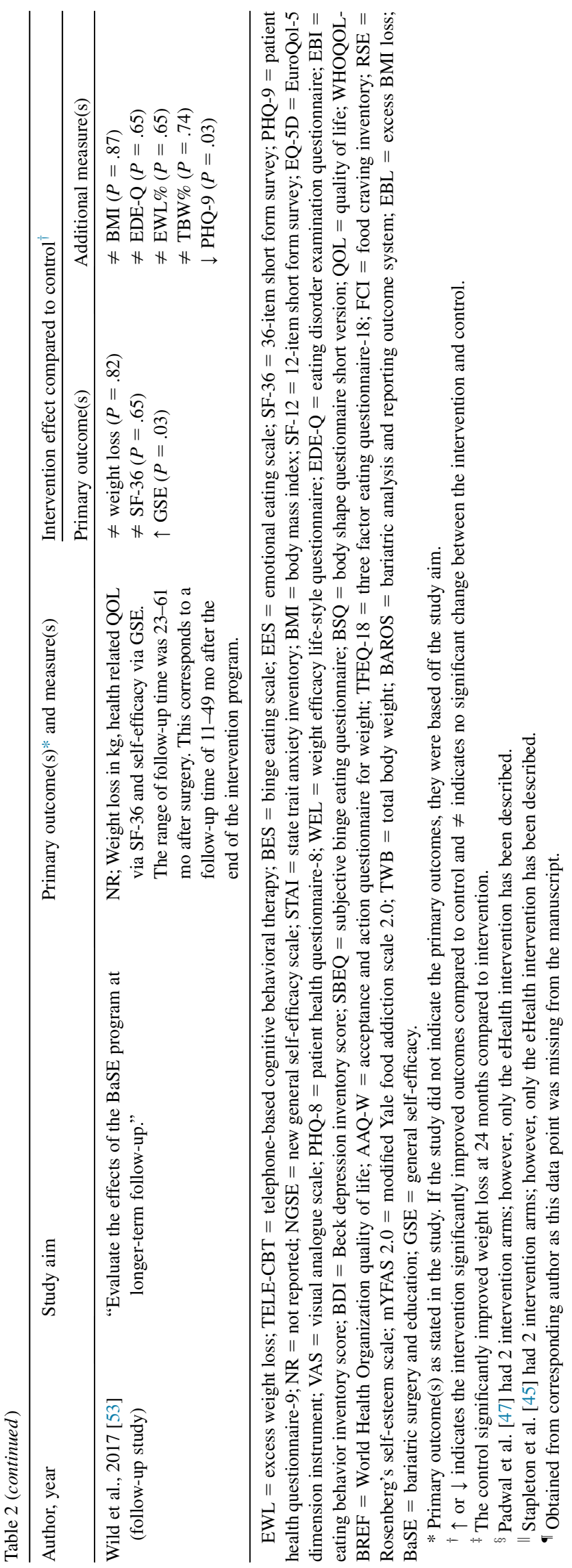

acceptance of weight-related thoughts and feelings [51,54], self-care knowledge [58], anxiety [58], adherence to preoperative exercise advice [43], appointment adherence [48], and rate of dropout [48]. No studies reported dietary intake-related outcomes as a primary outcome. The heterogeneity of assessment methods used between the included studies made quantitative comparisons difficult; thus, qualitative descriptions have been provided.

\section{Effect of eHealth on weight loss}

Both eHealth intervention and control groups lost weight across the included studies. Associated measures of effectiveness can be seen in Table 2. There was a high degree of variability in measures used to assess weight loss, including BMI [44,45,47,50,52,53,]], excess BMI lost [57], total body weight percentage [44,48,52,53,55], excess weight loss percentage $[42,44,52,53,57]$, and total body weight in kilograms $[47,52,53,56]$. The results for each outcome measure can be seen in Table S4. Overall, eHealth was found to be as effective as or more effective regarding weight loss compared with control groups, in all except 1 study where the control significantly improved weight loss percentage [55]. While some studies compared eHealth (without usual care) with usual or minimal care [42,43,4549,51,54-56,58], few measured weight loss, and those that did showed an equal effect, except for 1 that improved weight loss at the end of a preoperative intervention [56]. Studies that delivered eHealth plus usual care, compared with usual care [44,50,52,53,57], similarly showed equal effect, except for 1 study by Mangieri et al. [57] that found the intervention significantly improved excess weight and BMI loss.

\section{Weight loss maintenance}

Two studies (reported across 4 publications) reported postintervention follow-up [52,53,55,56], which allowed weight loss maintenance to be determined (Table 3). In the study by Kalarchian et al. [55,56], participants maintained their weight loss at 12 months: $27.4 \%$ versus $29.4 \%$ for intervention and control respectively $(P=$ .12). Between 12 and 24 months, participants in the intervention group had regained approximately $1 \%$. Overall, the percentage weight loss of $26.5 \%$ remained higher than $22.8 \%$ at postintervention (3 months postoperatively). The control group maintained their weight, with $29.5 \%$ weight loss at 24 months. In the study by Wild et al. [52,53], all participants continued to lose weight between 6 and 12 months. Between 12 and 24 months, all participants regained weight, with the intervention group gaining a mean of $5.2 \mathrm{~kg}$ and the control group a mean of $3.8 \mathrm{~kg}$. Overall, they remained below the weights recorded at 6 months. 
Table 3

Weight maintenance results of included studies with eHealth interventions delivered to adults who are scheduled for or have undergone bariatric surgery

\begin{tabular}{|c|c|c|c|c|c|}
\hline Time points postoperatively & Group & Weight $(\mathrm{kg})$ & $\mathrm{BMI}\left(\mathrm{kg} / \mathrm{m}^{2}\right)$ & EWL\% & TBW\% \\
\hline \multicolumn{6}{|c|}{ Kalarchian et al. 2013 [56] and Kalarchian et al., 2016 [57] } \\
\hline \multirow[t]{2}{*}{$6 \mathrm{mo}^{*}$} & Intervention & - & - & - & 22.9 \\
\hline & Control & - & - & - & 24.4 \\
\hline & Control & - & - & - & 29.4 \\
\hline \multirow[t]{2}{*}{$24 \mathrm{mo}$} & Intervention & - & - & - & 26.5 \\
\hline & Control & - & - & - & 29.5 \\
\hline & Control & 112.3 & 37.8 & 50.7 & 24.4 \\
\hline \multirow[t]{2}{*}{$12 \mathrm{mo}$} & Intervention & 99.1 & 33.5 & 67.1 & 32.9 \\
\hline & Control & 99.8 & 33.7 & 65.9 & 32.5 \\
\hline \multirow[t]{2}{*}{$23-61 \mathrm{mo}$} & Intervention & 104.3 & 35.2 & 60.3 & 30.0 \\
\hline & Control & 103.6 & 35.0 & 62.1 & 29.4 \\
\hline
\end{tabular}

$\mathrm{BMI}=$ body mass index; $\mathrm{EWL}=$ excess weight loss; TBW $=$ total body weight.

* The end of the intervention was at 3 months postoperatively. The second publication included follow-up at 12 and 24 months postoperatively, which is $\geq 6$ months after final intervention contact. While there was no data for end of intervention at 3 months post operatively, data at 6 months was available.

${ }^{\dagger}$ The initial publication reported outcomes measured at at 6 month and 12 months post operatively [52]. The follow-up publication reported on outcomes measured 23-61 months after surgery; corresponding to a follow-up time of 11-49 months after the end of the intervention program. The duration of the intervention is unclear, and end of intervention data were not reported. However, data at 6 months postoperatively were available. It reasonable to suspect measurements at 12 and 23-61 months postoperatively would be $\geq 6$ months after final intervention contact.

Effect of eHealth on eating psychopathology, quality of life, depression screening, and self-efficacy

\section{Eating psychopathology}

Six studies (reported across 8 publications), involving 562 participants, measured eating psychopathology [45,46,49,51-54,56]. Associated measures of effectiveness can be seen in Table 2. There was large diversity regarding outcome measures used to assess eating psychopathology. The interventions showed significant improvement on eating disorder examination [51,54], subjective binge eating [51], modified Yale Food Addiction Scale (YFAS) [49], binge eating scale [46], emotional eating scale [46], eating behavior inventory [56], and Three-Factor Eating Questionnaire (TFEQ) [45]. Further details can be seen in Table S5.

\section{Quality of life}

Five studies (reported across 7 publications), involving 716 participants, measured quality of life [44,46,47,51-54]. Associated measures of effectiveness can be seen in Table 2. The interventions showed significant improvement on the World Health Organization Quality of Life assessment (WHOQOL) [51,54], and EuroQol-5 Dimension 9EQ-5D) on the visual analog scale (VAS) [47]. The intervention showed an equal effect to the control for all other measures. Further details can be seen in Table S5.

\section{Depression screening}

Four studies (reported across 5 publications), involving 768 participants, screened for depression $[45,47,52,53,56]$. Associated measures of effectiveness can be seen in Table 2. A significant effect for the intervention over the control was seen for Patient Health Questionnaire Version 9 (PHQ-9) [46]. Further details can be seen in Table S5.

\section{Self-efficacy}

Three studies (reported across 4 publications), involving 574 participants, measured self-efficacy [47,52,53,58]. Associated measures of effectiveness can be seen in Table 2. A significant difference was seen for results on the weight efficacy life-style questionnaire [47], new general self-efficacy questionnaire [58], and general selfefficacy [52,53], showing intervention effect over control. Further details can be seen in Table S5.

\section{Subgroups}

Five studies, reported across 6 publications $[42,46,48,52,55,56]$, conducted further analysis on subgroups including procedure type (i.e., laparoscopic adjustable gastric banding versus laparoscopic sleeve gastrectomy), those with and without food addiction, rurality index (i.e., urban versus non-urban), those with and without clinically significant depression symptoms, as well as gender, BMI, age, and preoperative weight loss. Results have been tabulated and can be seen in Table S6.

\section{Study quality}

Overall bias was low for 5 reports ]43-46,52], had some concerns for 7 reports $[47,49,51,53-56]$, and high risk for 5 reports $[42,48,50,57,58]$. The risk of bias for "selection of reported results," "measurement of the outcome," and "deviations from intended interventions" were generally low (Fig. 2). For the randomization process, $41 \%$ of studies 


\section{Risk of bias}

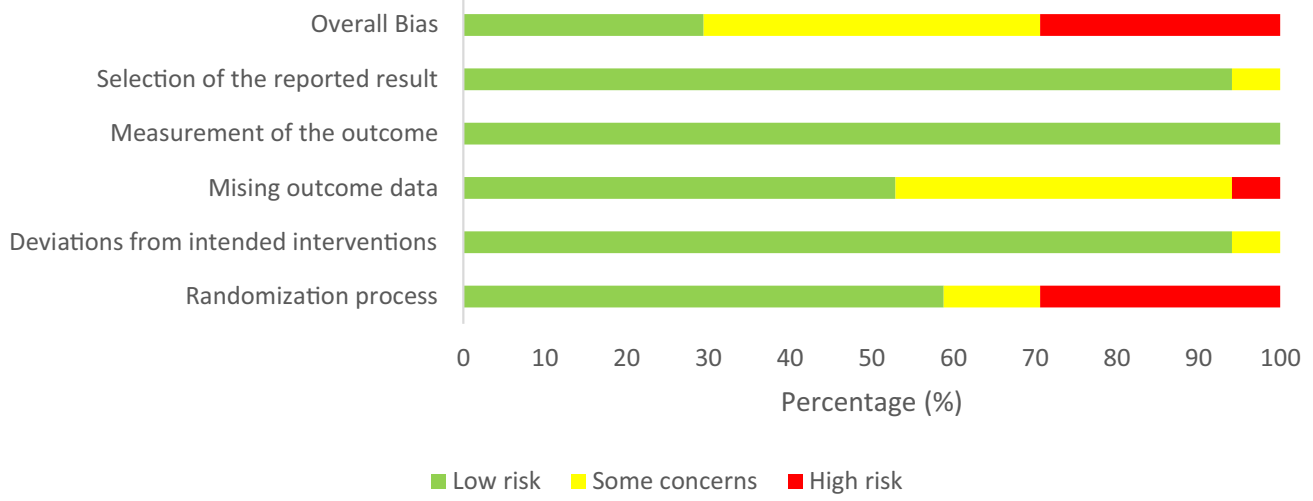

Fig. 2. Risk of bias graph: review authors' judgments about each risk of bias item presented as percentages across all included studies with eHealth interventions delivered to adults who are scheduled for or have undergone bariatric surgery.

$(\mathrm{n}=7)$ had some concerns or high risk; $47 \%$ had some concerns or high risk for missing outcome data $(\mathrm{n}=8)$.

\section{Discussion}

This systematic review aimed to evaluate the effect of complementing or substituting care with eHealth interventions on postoperative weight loss, weight loss maintenance, eating psychopathology, quality of life, depression screening, and self-efficacy in patients who are scheduled for or have undergone bariatric surgery. Given the rapid adoption of eHealth owing to COVID-19, a better understanding of the impact of eHealth has the potential to significantly inform bariatric health services that facilitate preand postoperative consultation and interventions for patients. Results showed no significant difference between the intervention and control groups for weight loss and weight maintenance; however, eHealth significantly improved various assessments for eating psychopathology. When bariatric surgery patients have limited or no access to health care teams or require additional support, eHealth may be a suitable option.

Overall, there was generally an equal effect of the eHealth interventions on weight loss compared with control groups. Therefore, eHealth could be offered to patients when they have limited or no access to health care teams or require additional support. To a lesser extent, eHealth was found to be more effective, and in 1 study negative effect was observed where the control significantly improved weight loss percentage compared with the intervention [55]. Current literature, with nonsurgical patients, has shown strong evidence that weight loss occurs in the short term because of eHealth and moderate evidence for the medium term [25,61]. It is speculated that no difference was seen in weight loss outcomes owing to the considerable postoperative weight loss related to the procedure itself. The role of eHealth in supporting weight loss for adults who undergo bariatric surgery remains unclear, and clarity is needed regarding whether eHealth is simply a delivery mechanism for interventions or whether it can change the nature of interventions [62].

Regarding weight loss maintenance, of the 2 studies (reported across 4 publications) available, participants demonstrated continued weight loss 6 months after the intervention (12 months postoperatively). This trend stopped 18 months after the intervention (24 months postoperatively) and weight regain was observed in both the intervention and control groups. Weight regain is a common occurrence associated with all weight loss modalities including bariatric surgery [6,63-65]. Underlying causes leading to weight regain are multifactorial [6], and given the prevalence of postoperative weight regain efforts have been focused on developing treatment options including lifestyle interventions [8], behavior management [9], and cognitive behavior therapy [63]. Of the included studies, none specifically targeted adults who had undergone bariatric surgery and regained weight. The eligibility criteria of the current review excluded studies without a control group, which excluded studies with interventions that targeted weight regain $[66,67]$. Studies that have investigated the efficacy of rescue interventions, such as Bradley et al. [67] and Kalarchian et al. [68], may also provide practical knowledge that can be transferred into interventions using eHealth modalities.

Successful weight loss and prevention of postoperative weight regain requires a behavioral change in combination with lifestyle modification. Behavior change interventions are typically complex, involving many interacting components [69], which can make it challenging to synthesize in reviews, replicate in research, and practically implement [39]. In the present review, techniques from the BCTT (v1) were only reported when explicitly stated by the authors. Findings may be limited by this coding decision and the lack of detailed reporting of BCTs within the included studies makes it difficult to draw concrete conclusions 
regarding the use of specific strategies in this context. Of the 36 techniques identified in the eHealth interventions [39], the most common techniques were self-monitoring, problem solving, social support, goal setting, and shaping knowledge, which is consistent with other systematic reviews exploring weight loss and weight maintenance eHealth interventions [70], postoperative behavioral management [9], and diet and physical activity interventions [40,71,72]. Consolidated Standards of Reporting Trials (CONSORT) guidelines call for precise reporting of behavior change interventions, including a "description of the different components of the interventions" [73]. While the included studies all provided detail regarding intervention content, the active components of behavior change were often described with different labels; for example, self-monitoring could be labeled as food diaries. In addition, the same labels could be applied to different techniques (e.g., "counseling" could involve "shaping knowledge" or "feedback and monitoring") and hence could not be coded owing to the subjectivity. It is recommended that future studies report interventions as per the BCTT as this will "lay the foundation for the reliable and systematic specification of behavior change interventions" in this field or research [39].

eHealth may serve to counter eating psychopathology, as interventions showed statistically significant improvement on various assessments. This is encouraging considering disordered eating and binge eating are common in patients who undergo bariatric surgery [74,75] and are associated with less weight loss and/or more weight regain postoperatively $[75,76]$. Notably, the studies with intervention effect included acceptance and commitment therapy [51,54], cognitive behavioral therapy $[46,49]$, emotional freedom techniques [45], or a behavior lifestyle intervention [56]. Current evidence regarding psychosocial interventions for bariatric surgery patients is strongest for the impact of cognitive behavioral therapy on improving disordered eating behaviors and eating pathology [77]. The optimal time to initiate treatment is thought to be early in the postoperative period before significant problematic eating behaviors and weight regain occur [77]. A systematic approach to postoperative patient assessment may be of benefit to identify patients at risk of weight regain and hence a potential candidate for further support. It should be noted that, like weight loss, clarity is needed regarding whether eHealth is a delivery mechanism for interventions such as cognitive behavioral therapy or whether it changes the nature of the treatment [62]. Further research is required to answer this relevant clinical question.

Modalities varied across the interventions, including traditional telehealth methods (telephone, email, and internet) and eHealth (mobile applications, text messaging programs, and WiFi devices). Four studies delivered postoperative interventions without usual care and 4 delivered postoperative interventions in addition to usual care. Of those delivered in addition to usual care, 3 implemented a combination of modalities. There was no indication of a stepped care approach; rather, components were all provided at the same time. The 2019 updated AACE/TOS/ ASMS Clinical Practice Guideline recommends postoperative "interventions should first include dietary change, physical activity, behavioral modification with frequent followup, and then, if appropriate, pharmacologic therapy and/or surgical revision" [2]. eHealth can provide additional options to increase the availability of support and address behavior modification before resorting to more intense approaches. Stepped care is an increasingly popular treatment model to overcome discrepancies between the demand and supply of healthcare services and reduce the existing healthcare burden [78]. Benefits of stepped care models include minimal interventions that can provide equivalent health gains, making current healthcare resources available to be used more efficiently, and it is generally well accepted by patients and professionals [79].

A case for stepped care for weight management after bariatric surgery was presented by Kalarchian et al. [80], suggesting it could begin with careful self-monitoring postoperatively via eHealth modalities such as mobile applications and weight-transmitting WiFi scales. A stepped eHealth approach would see patients offered a lowintensity and cost-effective intervention first, followed by stepping up to more intensive, expensive, and laborious treatments that are necessary based on outcomes [80], such as weight regain, clinically significant depression symptoms, and food addiction symptomology. In addition, the impact of COVID-19 and public health responses have necessitated a shift from in-person to remotely delivered bariatric care. The rapid uptake of eHealth has been instrumental in extending care to patients during the pandemic [81]. Psychosocial intervention to support mental health and bariatric care during COVID-19 could also follow a stepped approach. Starting with shaping knowledge and stress management followed by self-management via mobile applications, expanding support via videoconferencing or virtual support groups, and as required delivering virtual cognitive behavioral therapy [81].

The strengths of this review include a thorough search strategy, 2 independent review authors, and risk of bias assessment with the Cochrane tool. Limitations include substantial heterogeneity, which made quantitative comparisons difficult; hence, qualitative descriptions have been provided. One publication was transcribed using Google Translate, and we acknowledge that extraction via this method is more prone to error than extraction of English language articles [38]. While the search was conducted sometime after COVID-19 affected society, none of the included studies were conducted in the context of the pandemic. This will be an important consideration for future reviews, and with time, studies may be able to compare eHealth delivered during the pandemic with historical control groups to gain further insight. Research in this area, especially with the 
pre-bariatric surgery population, is still in preliminary stages. Further research studies are needed to better understand if eHealth can support postoperative success. This review focused on including studies with control conditions and, as a result, studies without a control were excluded that may be able to add valuable insight.

\section{Conclusion}

When bariatric surgery patients have limited or no access to healthcare teams or require additional support, eHealth may be a suitable option, given that it was found to deliver an equal effect or be more effective for weight loss. Furthermore, eHealth may counter eating psychopathology, which is positive given the known impact disordered eating and binge eating have on postoperative weight loss and weight maintenance. Of the available follow-up studies, both eHealth and control groups demonstrated weight gain in the longer term. Future studies implementing eHealth interventions would benefit from reporting intervention components as per the BCTT and further consideration of delivering eHealth in a stepped care approach would be beneficial.

\section{Disclosures}

The authors have no commercial associations that might be a conflict of interest in relation to this article.

CW is supported through an Australian Government RTP Stipend for academic Doctor of Philosophy program.

\section{Acknowledgements}

The authors thank Michelle DuBroy, Science Librarian at Griffith University, for assisting in the development of the literature search strategy.

\section{Supplementary materials}

Supplementary material associated with this article can be found, in the online version, at https://doi.org/10.1016/ j.soard.2021.07.020.

\section{References}

[1] Colquitt JL, Pickett K, Loveman E, Frampton GK. Surgery for weight loss in adults. Cochrane Database Syst Rev 2014;(8):CD003641.

[2] Mechanick JI, Apovian C, Brethauer S, et al. Clinical practice guidelines for the perioperative nutrition, metabolic, and nonsurgical support of patients undergoing bariatric procedures-2019 update: cosponsored by American Association of Clinical Endocrinologists/ American College of Endocrinology, the Obesity Society, American Society for Metabolic \& Bariatric Surgery, Obesity Medicine Association, and American Society of Anesthesiologists. Endocr Pract 2019;25(12):1346-59.

[3] Madsbad S, Dirksen C, Holst J. Mechanisms of changes in glucose metabolism and bodyweight after bariatric surgery. Lancet Diabetes Endocrinol 2014;2(2):152-64.
[4] Loveman E, Frampton G, Shepherd J, et al. The clinical effectiveness and cost-effectiveness of long-term weight management schemes for adults: a systematic review. Health Technol Assess 2011;15(2):1-182.

[5] Magro DO, Geloneze B, Delfini R, Pareja BC, Callejas F, Pareja JC. Long-term weight regain after gastric bypass: a 5-year prospective study. Obes Surg 2008;18(6):648-51.

[6] Karmali S, Brar B, Shi X, Sharma AM, De Gara C, Birch DW. Weight recidivism post-bariatric surgery: a systematic review. Obes Surg 2013;23(11):1922-33.

[7] Sarwer DB, Dilks RJ, West-Smith L. Dietary intake and eating behavior after bariatric surgery: threats to weight loss maintenance and strategies for success. Surg Obes Relat Dis 2011;7(5):644-51.

[8] Stewart F, Avenell A. Behavioural interventions for severe obesity before and/or after bariatric surgery: a systematic review and metaanalysis. Obes Surg 2016;26(6):1203-14.

[9] Rudolph A, Hilbert A. Post-operative behavioural management in bariatric surgery: a systematic review and meta-analysis of randomized controlled trials. Obes Rev 2013;14(4):292-302.

[10] Compher CW, Hanlon A, Kang Y, Elkin L, Williams NN. Attendance at clinical visits predicts weight loss after gastric bypass surgery. Obes Surg 2012;22(6):927-34.

[11] Poole NA, Atar AA, Kuhanendran D, et al. Compliance with surgical after-care following bariatric surgery for morbid obesity: a retrospective study. Obes Surg 2005;15(2):261-5.

[12] Funnell MM, Anderson RM, Ahroni JH. Empowerment and selfmanagement after weight loss surgery. Obes Surg 2005;15(3):417-22.

[13] Toussi R, Fujioka K, Coleman K. Pre-and postsurgery behavioral compliance, patient health, and postbariatric surgical weight loss. Obesity 2009;17(5):996-1002.

[14] Bourke L, Humphreys JS, Wakerman J, Taylor J. Understanding rural and remote health: a framework for analysis in Australia. Health Place 2012;18(3):496-503.

[15] Sivagnanam P, Rhodes M. The importance of follow-up and distance from centre in weight loss after laparoscopic adjustable gastric banding. Surg Endosc 2010;24(10):2432-8.

[16] Moroshko I, Brennan L, O’Brien P. Predictors of attrition in bariatric aftercare: a systematic review of the literature. Obes Surg 2012;22(10):1640-7.

[17] Hochberg LS, Murphy KD, O’Brien PE, Brennan L. Laparoscopic Adjustable Gastric Banding (LAGB) aftercare attendance and attrition. Obes Surg 2015;25(9):1693-702.

[18] Sarwer DB, Heinberg LJ. A review of the psychosocial aspects of clinically severe obesity and bariatric surgery. Am Psychol 2020;75(2):252-64.

[19] Bradford NK, Caffery LJ, Smith AC. Telehealth services in rural and remote Australia: a systematic review of models of care and factors influencing success and sustainability. Rural Remote Health 2016;16(4):4268.

[20] Ekeland AG, Bowes A, Flottorp S. Effectiveness of telemedicine: a systematic review of reviews. Int J Med Inform 2010;79(11):736-71.

[21] World Health Organization [homepage on the Internet]. Geneva, Switzerland: The Organization; [updated 2016 Dec 15; cited 2021 May 14]. Global diffusion of eHealth: making universal health coverage achievable: report of the third global survey on eHealth; [about 384 screens]. Available from: https://apps.who.int/iris/ bitstream/handle/10665/252529/9789241511780-eng.pdf? sequence $=1$ \&isAllowed $=\mathrm{y}$.

[22] World Health Organization [homepage on the Internet]. Geneva, Switzerland: The Organization; [updated 2019 Jun 6; cited 2021 May 14]. WHO guideline: recommendations on digital interventions for health system strengthening: web supplement 2: summary of findings and GRADE tables [about 210 screens]. Available from: https:// apps.who.int/iris/bitstream/handle/10665/324998/WHO-RHR-19.7eng.pdf?ua $=1$. 
[23] Maurice AP, Punnasseril JEJ, King SE, Dodd BR. Improving access to bariatric surgery for rural and remote patients: experiences from a state-wide bariatric telehealth service in Australia. Obes Surg 2020;30(11):4401-10.

[24] Musial J, Healy R, Campbell K, Wright C. Perspectives on technology use to enhance self- management in bariatric surgery patients. Nutr Diet 2020;77(S1):7-110.

[25] Hutchesson MJ, Rollo ME, Krukowski R, et al. eHealth interventions for the prevention and treatment of overweight and obesity in adults: a systematic review with meta-analysis. Obes Rev 2015;16(5):376-92.

[26] Arem H, Irwin M. A review of web-based weight loss interventions in adults. Obes Rev 2011;12(5):e236-43.

[27] Ryan K, Dockray S, Linehan C. A systematic review of tailored eHealth interventions for weight loss. Digit Health 2019;5. 2055207619826685.

[28] Bennett CB, Ruggero CJ, Sever AC, Yanouri L. eHealth to redress psychotherapy access barriers both new and old: a review of reviews and meta-analyses. J Psychother Integration 2020;30(2):188-207.

[29] Athanasiadis DI, Hernandez E, Hilgendorf W, et al. How are bariatric patients coping during the coronavirus disease 2019 (COVID-19) pandemic? Analysis of factors known to cause weight regain among postoperative bariatric patients. Surg Obes Relat Dis 2021;17(4):756-64.

[30] Conceição E, De Lourdes M, Ramalho S, Félix S, Pinto-Bastos A, Vaz AR. Eating behaviors and weight outcomes in bariatric surgery patients amidst COVID-19. Surg Obes Relat Dis 2021;17(6):116574.

[31] Coldebella B, Armfield NR, Bambling M, Hansen J, Edirippulige S. The use of telemedicine for delivering healthcare to bariatric surgery patients: a literature review. J Telemed Telecare 2018;24(10):651-60.

[32] Messiah SE, Sacher PM, Yudkin J, et al. Application and effectiveness of eHealth strategies for metabolic and bariatric surgery patients: A systematic review. Digit Health 2020;6:20552076198989872055207619898987.

[33] Moher D, Liberati A, Tetzlaff J, Altman DG. Preferred reporting items for systematic reviews and meta-analyses: the PRISMA statement. Int J Surg 2010;8(5):336-41.

[34] Page MJ, McKenzie JE, Bossuyt PM, et al. The PRISMA 2020 statement: an updated guideline for reporting systematic reviews. BMJ 2021;372:n71.

[35] Clark JM, Sanders S, Carter M, et al. Improving the translation of search strategies using the Polyglot Search Translator: a randomized controlled trial. J Med Libr Assoc 2020;108(2):195-207.

[36] Sogg S, Lauretti J, West-Smith L. Recommendations for the presurgical psychosocial evaluation of bariatric surgery patients. Surg Obes Relat Dis 2016;12(4):731-49.

[37] Marshall S, Mackay H, Matthews C, Maimone IR, Isenring E. Does intensive multidisciplinary intervention for adults who elect bariatric surgery improve post-operative weight loss, co-morbidities, and quality of life? A systematic review and meta-analysis. Obes Rev 2020;21(7):e13012.

[38] Balk EM, Chung M, Chen ML, Trikalinos TA, Chang LKW. Assessing the accuracy of Google translate to allow data extraction from trials published in non-English languages. AHRQ Methods for Effective Health Care [monograph on the Internet]. Rockville (MD): Agency for Healthcare Research and Quality (US); 2013 Jan [cited 2021 Jul 20]. Available from: https://www.ncbi.nlm.nih.gov/books/NBK1213 $04 \%$.

[39] Michie S, Richardson M, Johnston M, et al. The behavior change technique taxonomy (v1) of 93 hierarchically clustered techniques: building an international consensus for the reporting of behavior change interventions. Ann Behav Med 2013;46(1):81-95.

[40] Cradock KA, ÓLaighin G, Finucane FM, Gainforth HL, Quinlan LR, Ginis KAM. Behaviour change techniques targeting both diet and physical activity in type 2 diabetes: A systematic review and metaanalysis. Int J Behav Nutr Phys Act 2017;14(1):18.

[41] Higgins JP, Green S, editors. Cochrane handbook for systematic reviews of interventions, Chichester, England: John Wiley \& Sons; 2011., Version 5.1.0.

[42] Brown WA, Burton PR, Shaw K, et al. A pre-hospital patient education program improves outcomes of bariatric surgery. Obes Surg 2016;26(9):2074-81.

[43] Lemanu DP, Singh PP, Shao RY, et al. Text messaging improves preoperative exercise in patients undergoing bariatric surgery. ANZ J Surg 2018;88:733-8.

[44] Lauti M, Kularatna M, Pillai A, Hill AG, MacCormick AD. A randomised trial of text message support for reducing weight regain following sleeve gastrectomy. Obes Surg 2018;28(8):2178-86.

[45] Stapleton P, Clark A, Sabot D, Carter B, Leech K. Portion perfection and Emotional Freedom Techniques to assist bariatric patients post surgery: a randomised control trial. Heliyon 2020;6(6):e04058.

[46] Cassin SE, Sockalingam S, Du C, Wnuk S, Hawa R, Parikh SV. A pilot randomized controlled trial of telephone-based cognitive behavioural therapy for preoperative bariatric surgery patients. Behav Res Ther 2016;80:17-22.

[47] Padwal RS, Klarenbach S, Sharma AM, et al. The evaluating selfmanagement and educational support in severely obese patients awaiting multidisciplinary bariatric care (EVOLUTION) trial: principal results. BMC Med 2017;15(1):46.

[48] Wang CD, Rajaratnam T, Stall B, Hawa R, Sockalingam S. Exploring the effects of telemedicine on bariatric surgery follow-up: a matched case control study. Obes Surg 2019;29(8):2704-6.

[49] Cassin S, Leung S, Hawa R, Wnuk S, Jackson T, Sockalingam SJN. Food addiction is associated with binge eating and psychiatric distress among post-operative bariatric surgery patients and may improve in response to cognitive behavioural therapy. Nutrients 2020;12(10):2905.

[50] Vilallonga R, Lecube A, Fort JM, Boleko MA, Hidalgo M, Armengol M. Internet of things and bariatric surgery follow-up: comparative study of standard and IoT follow-up. Minim Invasive Ther Allied Technol 2013;22(5):304-11.

[51] Weineland S, Arvidsson D, Kakoulidis TP, Dahl J. Acceptance and commitment therapy for bariatric surgery patients, a pilot RCT. Obes Res Clin Pract 2012;6(1):e1-90.

[52] Wild B, Hünnemeyer K, Sauer H, et al. A 1-year videoconferencingbased psychoeducational group intervention following bariatric surgery: results of a randomized controlled study. Surg Obes Relat Dis 2015;11(6):1349-60.

[53] Wild B, Hünnemeyer K, Sauer H, et al. Sustained effects of a psychoeducational group intervention following bariatric surgery: follow-up of the randomized controlled BaSE study. Surg Obes Relat Dis 2017;13(9):1612-8.

[54] Weineland S, Hayes S, Dahl J. Psychological flexibility and the gains of acceptance-based treatment for post-bariatric surgery: six-month follow-up and a test of the underlying model. Clin Obes 2012;2(12): $15-24$.

[55] Kalarchian MA, Marcus MD, Courcoulas AP, Cheng Y, Levine MD. Preoperative lifestyle intervention in bariatric surgery: a randomized clinical trial. Surg Obes Relat Dis 2016;12(1):180-7.

[56] Kalarchian M, Marcus M, Courcoulas A, Cheng Y, Levine M. Preoperative lifestyle intervention in bariatric surgery: initial results from a randomized, controlled trial. Obesity 2013;21(2):254-60.

[57] Mangieri CW, Johnson RJ, Sweeney LB, Choi YU, Wood JC. Mobile health applications enhance weight loss efficacy following bariatric surgery. Obes Res Clin Pract 2019;13(2):176-9.

[58] Lee HI, Park JS. The effect of pre-operative information through audiovisual media on self-care knowledge, self-efficacy, and state anxiety of patients before bariatric surgery. Korean J Adult Nurs 2020;32(4):421-31. 
[59] Mitchell JE, de Zwaan M. Psychosocial assessment and treatment of bariatric surgery patients, New York: Routledge Taylor \& Francis; 2012.

[60] Michie S, Van Stralen MM, West R. The behaviour change wheel: a new method for characterising and designing behaviour change interventions. Implement Sci 2011;6:42.

[61] Bacigalupo R, Cudd P, Littlewood C, Bissell P, Hawley MS, Buckley Woods H. Interventions employing mobile technology for overweight and obesity: an early systematic review of randomized controlled trials. Obes Rev 2013;14(4):279-91.

[62] Eccleston C. Can 'ehealth' technology deliver on its promise of pain management for all? Pain 2011;152(8):1701-2.

[63] Velapati SR, Shah M, Kuchkuntla AR, et al. Weight regain after bariatric surgery: prevalence, etiology, and treatment. Curr Nutr Rep 2018;7(4):329-34.

[64] Christou NV, Look D, Maclean LD. Weight gain after short- and longlimb gastric bypass in patients followed for longer than 10 years. Ann Surg 2006;244(5):734-40.

[65] Cooper TC, Simmons EB, Webb K, Burns JL, Kushner RF. Trends in weight regain following Roux-en-Y gastric bypass (RYGB) bariatric surgery. Obes Surg 2015;25(8):1474-81.

[66] Bradley LE, Forman EM, Kerrigan SG, et al. Project HELP: a remotely delivered behavioral intervention for weight regain after bariatric surgery. Obes Surg 2017;27(3):586-98.

[67] Bradley LE, Forman EM, Kerrigan SG, Butryn ML, Herbert JD, Sarwer DB. A pilot study of an acceptance-based behavioral intervention for weight regain after bariatric surgery. Obes Surg 2016;26(10):2433-41.

[68] Kalarchian MA, Marcus MD, Courcoulas AP, Cheng Y, Levine MD, Josbeno D. Optimizing long-term weight control after bariatric surgery: a pilot study. Surg Obes Relat Dis 2012;8(6):710-5.

[69] Craig P, Dieppe P, Macintyre S, Michie S, Nazareth I, Petticrew M. Developing and evaluating complex interventions: the new Medical Research Council guidance. BMJ 2008;337:a1655.

[70] Asbjørnsen R, Smedsrød M, Solberg Nes L, et al. Persuasive system design (PSD) principles and behavior change techniques (BCT) to stimulate motivation and adherence in eHealth interventions to support weight loss maintenance: scoping review. J Med Internet Res 2019;21(6):e14265.
[71] Rigby RR, Mitchell LJ, Hamilton K, Williams LT. The use of behavior change theories in dietetics practice in primary health care: a systematic review of randomized controlled trials. J Acad Nutr Diet 2020;120(7):1172-97.

[72] Spahn JM, Reeves RS, Keim KS, et al. State of the evidence regarding behavior change theories and strategies in nutrition counseling to facilitate health and food behavior change. J Am Diet Assoc 2010;110(6):879-91.

[73] Boutron I, Moher D, Altman DG, Schulz KF, Ravaud P. Extending the CONSORT statement to randomized trials of nonpharmacologic treatment: explanation and elaboration. Ann Intern Med 2008;148(4):295309.

[74] Dawes AJ, Maggard-Gibbons M, Maher AR, et al. Mental health conditions among patients seeking and undergoing bariatric surgery: a meta-analysis. JAMA 2016;315(2):150-63.

[75] Meany G, Conceição E, Mitchell JE. Binge eating, binge eating disorder and loss of control eating: effects on weight outcomes after bariatric surgery. Eur Eat Disord Rev 2014;22(2):87-91.

[76] Paul L, van der Heiden C, Hoek HW. Cognitive behavioral therapy and predictors of weight loss in bariatric surgery patients. Curr Opin Psychiatry 2017;30(6):474-9.

[77] David LA, Sijercic I, Cassin SE. Preoperative and post-operative psychosocial interventions for bariatric surgery patients: a systematic review. Obes Rev 2020;21(4):e12926.

[78] Richards DA, Bower P, Pagel C, et al. Delivering stepped care: an analysis of implementation in routine practice. Implement Sci 2012;7:3.

[79] Bower P, Gilbody S. Stepped care in psychological therapies: access, effectiveness and efficiency. Br J Psychiatry 2005;186(1):11-7.

[80] Kalarchian MA, Marcus MD. The case for stepped care for weight management after bariatric surgery. Surg Obes Relat Dis 2018;14(1):112-6.

[81] Sockalingam S, Leung SE, Cassin SE. The impact of coronavirus disease 2019 on bariatric surgery: redefining psychosocial care. Obesity 2020;28(6):1010-2.

[82] Maddison R, Whittaker R, Stewart R, et al. HEART: heart exercise and remote technologies: A randomized controlled trial study protocol. BMC Cardiovascr Disord 2011;11:26. 